06

\title{
Синтез и исследование электрических свойств диарсенида трикадмия с наногранулами MnAs
}

\author{
(c) Л.А. Сайпулаева, ${ }^{1}$ М.М. Гаджиалиев, ${ }^{1}$ З.Ш. Пирмагомедов, ${ }^{1}$ Т.Н. Эфрендиева, ${ }^{1}$ А.Г. Алибеков, ${ }^{1}$ \\ Ш.Б. Абдулвагидов, ${ }^{1}$ Н.В. Мельникова, ${ }^{2}$ В.С. Захвалинский, ${ }^{3}$ С.Ф. Маренкин ${ }^{4,5}$ \\ ${ }^{1}$ ДФИЦ РАН Институт ффизики им. Х.И. Амирханова, \\ 367003 Махачкала, Россия \\ ${ }^{2}$ Уральский фредеральный университет, Институт естественных наук и математики, \\ 620002 Екатеринбург, Россия \\ ${ }^{3}$ Белгородский государственный национальный исследовательский университет, \\ 308015 Белгород, Россия \\ ${ }^{4}$ Институт общей и неорганической химии им. Н.С. Курнакова РАН, \\ 119991 Москва, Россия \\ ${ }^{5}$ НИТУ „МИСиС“, \\ 119991 Москва, Россия \\ e-mail: I.saypulaeva@gmail.com
}

Поступило в Редакцию 20 марта 2019 г.

В окончательной редакции 2 февраля 2020 г.

Принято к публикации 2 февраля 2020 г.

Синтезированы образцы диарсенида трикадмия с наногранулами MnAs (MnAs - 44.7 mol.\%). Структура образцов исследована методами рентгенофазного анализа и электронной микроскопии. Исследованы электрические свойства диарсенида трикадмия с наногранулами MnAs в интервале температур 77-372 K. Обнаружено, что вольт-амперные характеристики симметричны относительно инверсии знака напряжения при данной температуре, их отклонение от омичности при определенном пороговом значении напряжения и уменьшение участка омичности с ростом температуры обусловлены увеличением вероятности пробоя в поле выше $5 \cdot 10^{4} \mathrm{~V} / \mathrm{m}$.

Ключевые слова: нанокомпозиты, вольт-амперные характеристики, сопротивление, отрицательный температурный коэффициент, тепловой пробой.

DOI: 10.21883/JTF.2020.07.49446.100-19

\section{Введение}

Исследование в одном материале магнитных и полупроводниковых свойств представляет интерес как с точки зрения развития спинтроники, так и для фундаментальных исследований. Фундаментальный интерес к исследованию магнитных полупроводников определяется тем, что в них существенную роль играют магнитные и обменные взаимодействия. Интерес к исследованиям узкозонного полупроводника диарсенида трикадмия обусловлен результатами теоретических [1] и экспериментальных работ [2], в которых обосновывается принадлежность арсенида кадмия к объемным дираковским полуметаллам. Диарсенид трикадмия обладает преимуществом перед другими, известными нам, объемными дираковскими полуметаллами $\mathrm{BiO}_{2}$ и $\mathrm{Na}_{3} \mathrm{Bi}[3,4]$ : он стабилен и демонстрирует высокую подвижность носителей заряда $\left(9 \cdot 10^{6} \mathrm{~cm}^{2} \cdot \mathrm{V}^{-1} \cdot \mathrm{s}^{-1}\right.$ при $\left.5 \mathrm{~K}\right)$, превышающую подвижность носителей заряда в графене [5].

Носители заряда в диарсениде трикадмия отличаются малой эффективной массой и высокой подвижностью. Вопрос о зонной структуре узкозонного полупроводника диарсенида трикадмия исследуется достаточно давно и в ряде работ, наряду с бесщелевым состоянием, пред- полагается инверсия зон [6]. Эволюция зон в тройных и четверных твердых растворах на основе арсенида кадмия представляет интерес как отдельная задача.

Марганец растворяется в диарсениде трикадмия, образуя широкую область тройных твердых растворов $\left(\mathrm{Cd}_{1-x} \mathrm{Mn}_{x}\right)_{3} \mathrm{As}_{2}$. Превышение содержания марганца приводит к образованию композита на основе диарсенида трикадмия, содержащего, наряду с твердым раствором $\left(\mathrm{Cd}_{1-x} \mathrm{Mn}_{x}\right)_{3} \mathrm{As}_{2}$, включения арсенида марганца. Ферромагнитная фаза арсенида марганца кристаллизуется в гексагональной решетке $P 63 / \mathrm{mmc}$ с параметрами элементарной ячейки $a=3.72 \AA$ и $c=5.71 \AA$. При комнатной температуре в MnAs c повышением давления наблюдался переход из гексагональной структуры типа NiAs симметрии $P 63 / \mathrm{mmc}$ в орторомбическую структуру типа MnP симметрии Рnma, переход происходит при давлении $P_{t r}=0.45 \mathrm{GPa}$ [7].

Соединение MnAs обладает ферромагнетизмом с температурой Кюри немного выше комнатной $(318 \mathrm{~K})$, что делает его перспективным материалом для использования в различных элементах спиновой электроники, функционирующих в терагерцовом диапазоне [8-10].

Цель настоящей работы - синтез композита диарсенида трикадмия с наногранулами MnAs и исследование 
механизма нарушения закона Ома с помощью измерения вольт-амперных характеристик (BAX) в области температур $77-372 \mathrm{~K}$.

\section{1. Материалы и методы исследования}

\section{1. Синтез}

Синтез сплавов диарсенида трикадмия с наногранулами MnAs проводился путем сплавления исходных порошков диарсенида трикадмия с марганцем согласно реакции $3 \mathrm{CdAs}_{2}+4 \mathrm{Mn} \rightarrow \mathrm{Cd}_{3} \mathrm{As}_{2}+4 \mathrm{MnAs}$. Объемные образцы $\mathrm{Cd}_{3} \mathrm{As}_{2}-\mathrm{MnAs}$ были синтезированы вакуумноампульным методом из отдельных элементов в графитизированных вакуумированных ампулах в электрической печи с автоматической регулировкой температуры с точностью до $1 \mathrm{~K}$ [11]. Для уменьшения эффекта переноса в свободный объем ампулы легколетучего компонента - мышьяка, ампула была помещена в изотермическую зону печи. Синтез проходил в несколько этапов. Во время первого этапа, который длился $2 \mathrm{~h}$, происходило расплавление кадмия. Во время второго этапа, продолжительностью $48 \mathrm{~h}$, происходило взаимодействие расплава кадмия и мелкодисперсного марганца с газообразным мышьяком. Во время третьего этапа, продолжительностью $96 \mathrm{~h}$, происходило взаимодействие расплава $\mathrm{Cd}_{3} \mathrm{As}_{2}$ с $\mathrm{MnAs}$ и последующая их гомогенизация. Закалка образца в водной среде комнатной температуры проводилась во время четвертого этапа со скоростью $13 \mathrm{~K} / \mathrm{s}$.

\section{2. Методика измерения $\mathrm{BAX}$ в области температур $77-372 \mathrm{~K}$}

BAX были измерены в диапазоне температур $77-372$ К. При измерении температурных зависимостей $\mathrm{BAX}$ образец с контактами помещался в герметически плотную камеру, заполненную газообразным гелием при атмосферном давлении, которая вначале опускалась в сосуд с жидким азотом для измерений в области температур $77-300 \mathrm{~K}$, а затем помещалась в термостат для измерений в интервале $300-372 \mathrm{~K}$. Электродвижущую силу на образце и показания медь-константановых термопар измеряли с помощью потенциометра Щ300. При измерении BAX в зависимости от температуры напряжение и ток снимались с помощью милливольтметра „KEITHLEY 2000“.

\section{Результаты и их обсуждение}

Диарсенид трикадмия с наногранулами состава $44.7 \mathrm{~mol} \% \mathrm{MnAs}$ представляет собой сложную систему, состоящую из ферромагнитных гранул MnAs, расположенных случайным образом в полупроводниковой матрице $\mathrm{Cd}_{3} \mathrm{As}_{2}$. Такая морфология обусловливает неравномерное распределение электрического поля в объеме

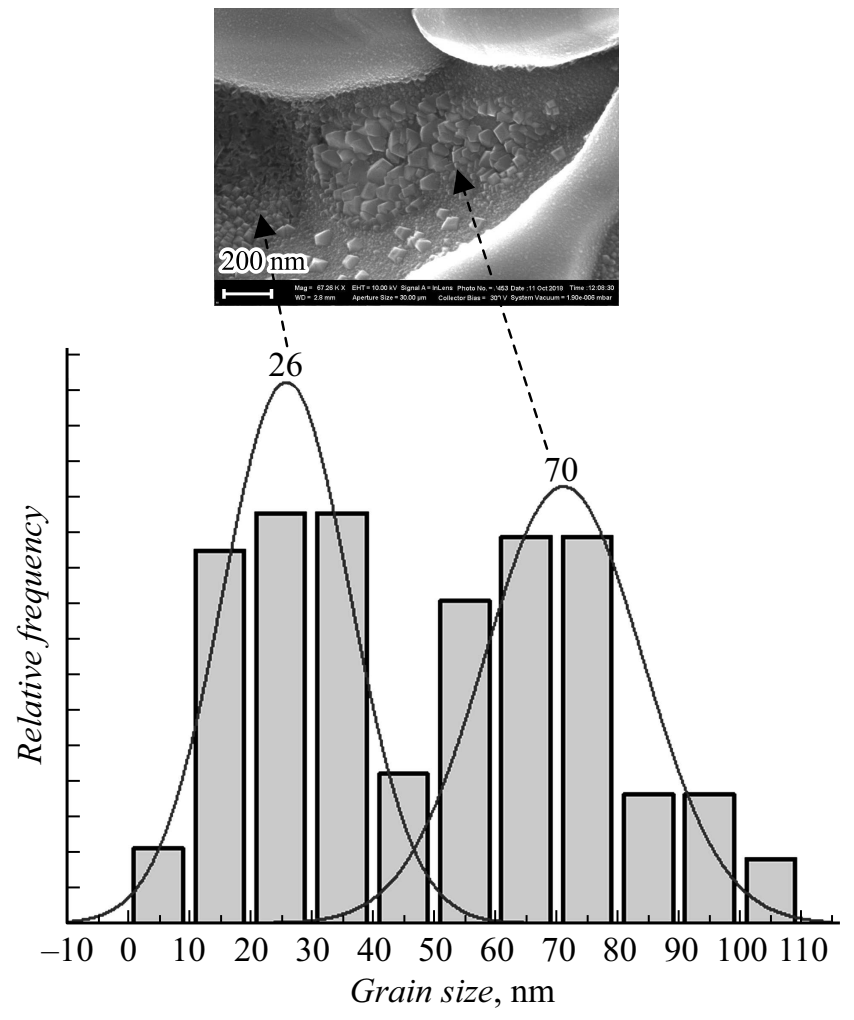

Рис. 1. Распределение нанокластеров MnAs по размерам в композите $\mathrm{Cd}_{3} \mathrm{As}_{2}+44.7 \mathrm{~mol} \% \mathrm{MnAs}$, полученное с помощью сканирующего электронного микроскопа (Merlin, CarlZeiss).

образца. Электронно-микроскопические исследования, проведенные с помощью силового электронного микроскопа (СЭМ) фирмы CarlZeissMerlin, подтвердили наличие наночастиц MnAs c характерными диаметрами от 10 до $50 \mathrm{~nm}$ внутри матрицы диарсенида трикадмия (рис. 1). Как видно из рисунка, в своем большинстве характерные диаметры нанокластеров MnAs составляют 20-30 nm. Отдельные экземпляры с размерами более $50 \mathrm{~nm}$, по нашему мнению, могут находиться только в приповерхностных областях, а не в объеме композита, так как это привело бы к существенному повышению энергий деформации как матрицы, так и ее вкраплений. Так что вполне обоснованно можно считать, что объемные физические свойства исследуемого нами композитного материала $\mathrm{Cd}_{3} \mathrm{As}_{2}+44.7 \mathrm{~mol} . \% \mathrm{MnAs}$ обусловлены нанокластерами MnAs с диаметрами от 20 до $30 \mathrm{~nm}$. Рентгенограмма нанокомпозита $\mathrm{Cd}_{3} \mathrm{As}_{2}+44.7 \mathrm{~mol} \% \mathrm{MnAs}$ (рис. 2) подтверждает, что он состоит из двух фаз: диарсенида трикадмия и арсенида марганца. Микроструктура образца свидетельствует об эвтектическом разделении расплава при отвердевании на систему из двух веществ: диарсенида трикадмия и арсенида марганца. Отличительной особенностью системы диарсенида трикадмия с наногранулами MnAs является наличие значительной области несмешиваемости расплавов диарсенида трикадмия и арсенида марганца, что отражается и в структуре 


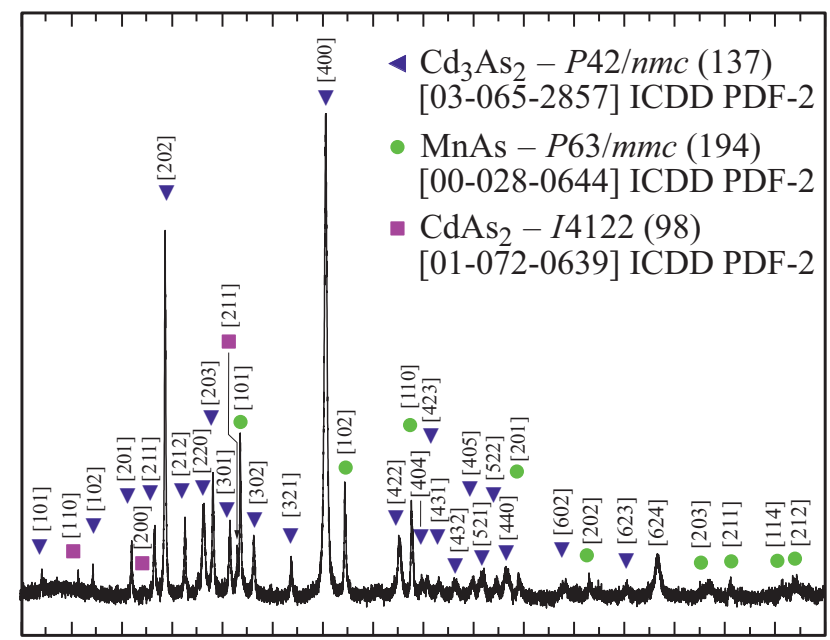

$10 \quad 1520 \quad 25 \quad 30 \quad 3540 \quad 4550 \quad 55 \quad 60 \quad 6570 \quad 75 \quad 80 \quad 8590$ $2 \Theta, \operatorname{deg}$

Рис. 2. Рентгенограмма образца $\mathrm{Cd}_{3} \mathrm{As}_{2}+44.7$ mol.\% MnAs.

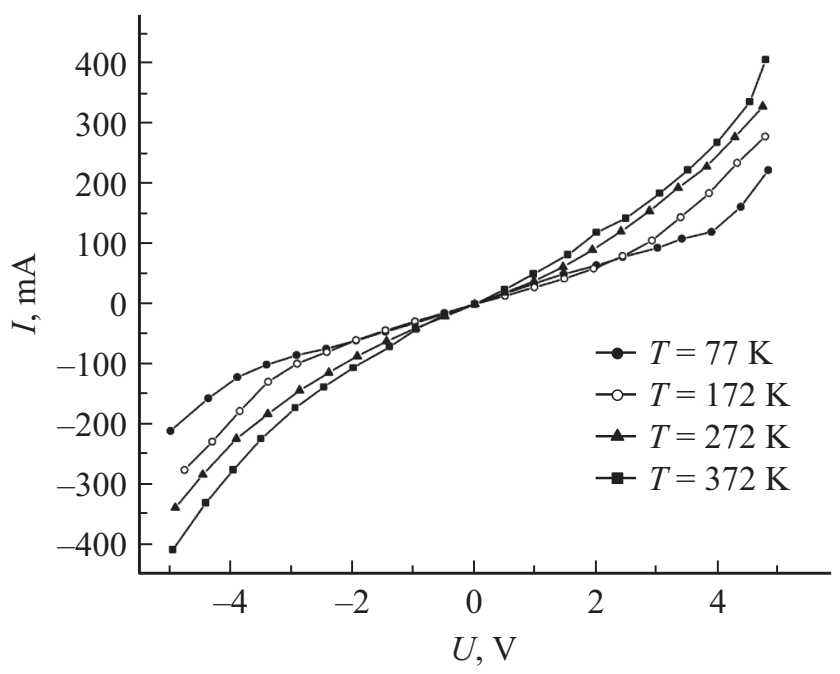

Рис. 3. Температурная зависимость ВАX композита $\mathrm{Cd}_{3} \mathrm{As}_{2}+44.7 \mathrm{~mol} . \% \mathrm{MnAs}$.

сплава. Такое практически однообразное расположение ферромагнитных наносфер почти одинаковых диаметров в немагнитной матрице является технологическим преимуществом при производстве из них магнитных носителей информации, так как упорядоченное расположение магнитных частиц в матрице происходит естественным образом.

BAX образца композита $\mathrm{Cd}_{3} \mathrm{As}_{2}+44.7$ mol.\% MnAs c размерами $4 \times 2 \times 1.5 \mathrm{~mm}$, измеренные в двух направлениях приложенного напряжения в интервале температур $77-372 \mathrm{~K}$, представлены на рис. 3. Характеристики симметричны при обоих направлениях тока. Можно четко выделить следующие участки ВАХ, например, для температуры $272 \mathrm{~K}: 1$ - участок при слабых электрических полях $U=2 \mathrm{~V}\left(E<5 \cdot 10^{4} \mathrm{~V} / \mathrm{m}\right)$ - линейный рост тока от напряжения, соответствующий омическому участку; 2 - участок при более высоких полях $\left(E>5 \cdot 10^{4} \mathrm{~V} / \mathrm{m}\right)$ - ВАХ отклоняется от омичности наблюдается отклонение тока от линейного роста. Как видно из рисунка, максимальная величина тока симметрично изменяется с температурой при смене направления прикладываемого напряжения: при $U=-5 \mathrm{~V}$ ток растет от -200 до $-400 \mathrm{~mA}$, а при $U=5 \mathrm{~V}$ - от 200 до $400 \mathrm{~mA}$ с ростом температуры. Кривые зависимости $I(U)$ качественно подобны друг другу, но при азотной температуре нелинейность проявляется при более высоких напряжениях и имеет более резкий характер. Из рисунка видно, что ВАХ соответствует ситуации, при которой ток течет по схеме металл-полупроводник и проявляет зависимости, характерные для структур с барьером в области контакта металла (MnAs) и полупроводника (прослойка из матрицы диарсенида трикадмия) [12].

Известно, что при сильном уменьшении высоты барьера с ростом напряжения концентрация неосновных носителей увеличивается по экспоненциальному закону $N=N_{0} e^{r t}$ (где $N-$ число неосновных носителей тока, $r$ - коэффициент пропорциональности, $t-$ время, в течение которого меняется высота барьера) и имеет место полевая эмиссия [12], что и наблюдается на эксперименте в области нарушения закона Ома.

Это объясняется тем, что с ростом температуры электроны в полупроводниковом слое диарсенида трикадмия вблизи барьера возбуждаются на более высокие энергетические уровни и соответственно вероятность туннельного прохождения барьера с ростом напряжения возрастает.

Из рис. 3 видно, что с ростом температуры уменьшается напряжение, при котором нарушается линейный, омический рост тока $(77 \mathrm{~K}-4 \mathrm{~V} ; 172 \mathrm{~K}-\sim 2.5 \mathrm{~V}$; $272 \mathrm{~K}-\sim 2 \mathrm{~V} ; 372 \mathrm{~K}-\sim 1.5 \mathrm{~V})$. Наблюдаемый отрицательный температурный коэффициент зависимости величины напряжения, при котором нарушается линейный рост тока от напряжения, свойственен случаю теплового пробоя в отличие от лавинного пробоя, имеющего место при положительном температурном коэффициенте.

\section{Заключение}

Экспериментальное исследование композита $\mathrm{Cd}_{3} \mathrm{As}_{2}+44.7 \mathrm{~mol} \%$ MnAs в области температур 77-372 K показало, что ВАХ симметричны при смене знака прикладываемого напряжения при данной температуре, но при низких температурах нелинейность $\mathrm{BAX}$ проявляется при более высоких напряжениях, что объясняется более высоким сопротивлением на барьере. C ростом температуры в слое полупроводника вблизи барьера, электроны возбуждаются на более высокие уровни, и растет вероятность прохождения барьера, что приводит к уменьшению области омичности. Основной механизм пробоя в этой области - тепловой пробой. 


\section{Конфликт интересов}

Авторы заявляют, что у них нет конфликта интересов.

\section{Список литературы}

[1] Wang Z., Weng H., Wu Q., Dai X., Fang Z. // Phys. Rev. 2013. Vol. 88. P. 125427.

[2] Borisenko S., Gibson Q., Evtushinsky D., Zabolotnyy V., Buchner B., Cava R.J. // Phys. Rev. Lett. 2014. Vol. 113. P. 027603.

[3] Liu Z.K., Zhou B., Zhang Y., Wang Z.J., Weng H.M., Prabhakaran D., Mo S.-K., Shen Z.X., Fang Z., Dai X., Hussain Z., Chen Y.L. // Science. 2014. Vol. 343. P. 864-867.

[4] Young S.M., Zaheer S., Teo J.C.Y., Kane C.L., Mele E.J., Rappe A.M. // Phys. Rew. Lett. 2012. Vol. 108. P. 14405.

[5] Liang T., Gibson Q., Ali M.N., Liu M., Cava R. J., Ong N.P. // Nat. Mater. 2015. Vol. 14. N 3. P. 280-284.

[6] Aubin M.J., Caron L.G., Jay-Gerin J.-P. // Phys. Rev. 1977. Vol. 15. P. 3872-3878.

[7] Грибанов И.Ф., Завадский Э.А., Сиваченко А.П. // ФТН. 1979. T. 5. C. $1219-1222$

[8] Spezzani C., Ferrari E., Allaria E., Vidal F., Ciavardini A., Delaunay R., Capotondi F., Pedersoli, Coreno M., Svetina C., Raimondi L., Zangrando M., Ivanov R., Nikolov I., Demidovich A., Danailov M.B., Popescu H., Eddrief M., De Ninno G., Kiskinova M., Sacchi M. // Phys. Rev. Lett. 2014. Vol. 113. N 24. P. 247202.

[9] Hubmann J., Bauer B., Korner H.S., Furthmeier S., Buchner M., Bayreuther G. // Nano Lett. 2016. Vol. 16. P. $900-905$.

[10] Novotortsev V.M, Marenkin S.F., Fedorchenko I.V., Kochura A.V. // Rus. J. Inorgan. Chem. 2010. Vol. 55. N 11. P. $1762-1773$.

[11] Kochura A.V., Marenkin S.F., Ril' A.I., Zheludkevich A.L., Abakumov P.V., Knjazev A.F., Dobromyslov M.B. // J. Nano Electron. Phys. 2015. Vol. 7. N 4. P. 04079(3p.).

[12] Sze S.M., Coleman D.J., Loya A. // Solid State Electron. 1971. Vol. 14. P. 1209-1218. 